\title{
Conjugated linoleic acid versus high-oleic acid sunflower oil: effects on energy metabolism, glucose tolerance, blood lipids, appetite and body composition in regularly exercising individuals
}

\author{
Estelle V. Lambert ${ }^{1}$, Julia H. Goedecke ${ }^{1}$, Kerry Bluett ${ }^{2}$, Kerry Heggie ${ }^{2}$, Amanda Claassen ${ }^{1}$, Dale E. Rae ${ }^{1}$, \\ Sacha West ${ }^{1}$, Jonathan Dugas ${ }^{1}$, Lara Dugas ${ }^{1}$, Shelly Meltzer ${ }^{1}$, Karen Charlton ${ }^{2}$ and Inge Mohede ${ }^{3}$ \\ ${ }^{1}$ UCT/MRC Research Unit for Exercise Science and Sports Medicine, Department of Human Biology, Faculty of Health Sciences, \\ University of Cape Town, PO Box 115 Newlands, 7725, South Africa \\ ${ }^{2}$ Nutrition and Dietetics Division, Department of Medicine, Faculty of Health Sciences, University of Cape Town, South Africa \\ ${ }^{3}$ Loders Croklaan Lipid Nutrition, The Netherlands
}

(Received 15 August 2005 - Revised 29 March 2006 - Accepted 10 May 2006)

\begin{abstract}
The aim of this study was to measure the effects of 12 weeks of conjugated linoleic acid (CLA) supplementation on body composition, RER, RMR, blood lipid profiles, insulin sensitivity and appetite in exercising, normal-weight persons. In this double-blind, randomised, controlled trial, sixty-two non-obese subjects (twenty-five men, thirty-seven women) received either $3.9 \mathrm{~g} / \mathrm{d}$ CLA or $3.9 \mathrm{~g}$ high-oleic acid sunflower oil for 12 weeks. Prior to and after 12 weeks of supplementation, oral glucose tolerance, blood lipid concentrations, body composition (dual-energy X-ray absorptiometry and computerised tomography scans), RMR, resting and exercising RER and appetite were measured. There were no significant effects of CLA on body composition or distribution, RMR, RER or appetite. During the oral glucose tolerance tests, mean plasma insulin concentrations $(0,30,120 \mathrm{~min})$ were significantly lower $(P=0.04)$ in women who supplemented with CLA (24.3 (SD 9.7) to 20.4 (SD 8.5) $\mu \mathrm{U} / \mathrm{ml})$ compared to high-oleic acid sunflower oil control (23.7 (SD 9.8) to 26.0 (SD 8.8) $\mu \mathrm{U} / \mathrm{ml}$ ). Serum NEFA levels in response to oral glucose were attenuated in both men and women in the CLA $(P=0.001)$ compared to control group. However, serum total cholesterol and LDL-cholesterol concentrations decreased in both groups and HDL-cholesterol concentrations decreased in women over 12 weeks $(P=0 \cdot 001, P=0 \cdot 02, P=0 \cdot 02$, respectively). In conclusion, mixed-isomer CLA supplementation had a favourable effect on serum insulin and NEFA response to oral glucose in non-obese, regularly exercising women, but there were no CLA-specific effects on body composition, energy expenditure or appetite.
\end{abstract}

Exercise metabolism: Insulin sensitivity: Body fat distribution: CLA isomers

There is recent scientific and clinical interest in conjugated linoleic acid (CLA), for its putative role in enhanced immune function, altered substrate metabolism and body composition changes. Linoleic acid is an 18-carbon PUFA with two double-bonds in the 9 and 12 positions (cis configuration). In CLA, the double bonds reside in either the 9 and 11 positions (predominant form in food), the 10 and 12 positions or the 11 and 13 positions. The primary dietary source of CLA is found in food products from ruminant animals, such as cheese, milk and meat.

In animal and tissue studies, CLA has been associated with lower blood lipid levels, reduced body fat accumulation and increased fat oxidation, increased lean mass accretion, improved skeletal muscle insulin sensitivity and reduced food intake (Houseknecht et al. 1998; Rahman et al. 2001). However, there appear to be large inter-species differences in response to CLA that may limit the interpretation or extrapolation to human studies. For example, Terpstra (2001) has estimated that the normalised, body fat-lowering effects of
CLA are 7-fold higher in mice than in man. Therefore, for the purposes of this paper, only the results of human studies will be discussed. However, human studies examining the metabolic effects of CLA supplementation show equivocal results.

A series of well-controlled studies undertaken at the University of California found that $64 \mathrm{~d}$ of CLA administration $(3.9 \mathrm{~g} / \mathrm{d})$ in seventeen healthy female volunteers did not result in changes in body composition, energy expenditure, substrate utilisation, appetite or plasma lipid profile (Medina et al. 2000; Zambell et al. 2000; Benito et al. 2001). Failure to show an effect in these studies may be due, in part, to low statistical power, or differences in isomer-specific efficacy. The CLA used in these studies contained less than $25 \% t 10 c 12$ and less than $18 \% c 9 t 11$ isomers. In contrast, studies including more than fifty free-living overweight volunteers found that CLA administration of $\geq 3.4 \mathrm{~g} / \mathrm{d}$ for 12 weeks was associated with significant reductions in body fat mass compared to placebo administration (Blankson et al. 2000).

\footnotetext{
Abbreviations: CLA, conjugated linoleic acid; CT, computerised tomography; DEXA, dual-energy X-ray absorptiometry; OGTT, oral glucose tolerance test; VAS, visual analogue scale.

* Corresponding author: Professor Estelle V. Lambert, fax +27 21 6867530, email vlambert@sports.uct.ac.za
} 
In a recent study, Kamphuis et al. (2003a), also found that CLA administration resulted in a significant increase in lean body mass and associated changes in resting metabolic rate, as well as reductions in appetite sensations.

Changes in body fat distribution have also been demonstrated with CLA supplementation. Risérus et al. (2001) demonstrated a significant decrease in sagittal abdominal area in a small sample of obese, middle-aged men with signs of the metabolic syndrome when supplemented with $4.2 \mathrm{~g} / \mathrm{d}$ of CLA for 4 weeks. However, they were unable to demonstrate any associated changes in blood lipids or glucose and insulin concentrations with CLA supplementation. In a follow-up study, the same group demonstrated that administration of $3.4 \mathrm{~g} / \mathrm{d}$ of an enriched $t 10 c 12$ CLA isomer for 12 weeks increased insulin resistance, fasting glucose and dyslipidaemia in abdominally obese men ( $n$ 19) (Risérus et al. 2002). However, these adverse metabolic effects were not found when a commercial CLA mixture $(35.9 \% t 10 c 12$ and $35.4 \% c 9 t 11$ ) was administered. Further to this study, 12 weeks of supplementation with a similar dose of predominantly $c 9 t 11$ isomer-enriched CLA resulted in a significant reduction in insulin sensitivity in abdominally obese men (Risérus et al. 2004a). Therefore, these studies highlight the complex relationships between CLA isomers and dose, metabolic phenotype, and the potential underlying mechanisms of effect of CLA in influencing glucose and lipid metabolism in vivo (Risérus et al. 2004a).

Furthermore, there are few studies in which these relationships have been interrogated in persons who are regularly exercising (Thom et al. 2001). This has important implications, as changes in substrate oxidation and tissue sensitivity to insulin associated with training may interact with the effects of CLA administration on body composition, glucose and lipid metabolism. Moreover, these individuals constitute a population who may be likely to use dietary supplements for health and weight control. By relating changes in adipose tissue mass to changes in whole body substrate oxidation and metabolism, satiety and energy intake, we may begin to understand the potential mechanisms underlying these effects.

The primary aim of the present study was, therefore, to measure the effects of CLA administration versus a higholeic acid sunflower oil control, on whole body substrate oxidation at rest and during exercise, resting energy expenditure, body composition and regional adipose tissue distribution in regularly exercising individuals. A secondary aim was to examine the effects of CLA on blood lipid profiles, glucose homeostasis and insulin sensitivity in already exercising, normal-weight persons.

\section{Methods}

\section{Subjects}

Sixty-four regularly exercising subjects (twenty-six men, thirty-eight women), between the ages of 21 and 45 were recruited from the fitness centre of the Sports Science Institute of South Africa or a similar facility. Persons were excluded on the basis of chronic illness or medication, existing lipid disorders, obesity $\left(\mathrm{BMI}>30 \mathrm{~kg} / \mathrm{m}^{2}\right)$, diabetes or hypertension. Women who were lactating or who were planning on becoming pregnant were also excluded. Individuals were also excluded if they were currently taking nutritional supplements, other than a general multi-vitamin supplement. Only subjects who were exercising three or more times per week, and who had been exercising at this level for more than 6 months, were included. Furthermore, subjects must have been weight stable $( \pm 2-3 \mathrm{~kg}$ ) for 3 months preceding the trial.

The subjects were informed of the nature of the trial, and all potential risks and benefits were explained to them. Informed written consent was obtained from all subjects before the start of the trial. The Research and Ethics Committees of the Faculty of Health Sciences, University of Cape Town, South Africa, approved the study.

\section{Protocol}

The study was a double-blind, controlled trial and the subjects were randomly assigned to one of two groups, receiving either 3.9 g CLA supplement (Formule Naturelle Ltd, Johannesburg, South Africa, containing Clarinol ${ }^{\mathrm{TM}}$ from Loders Croklaan, Lipid Nutrition, Wormerveer, The Netherlands) or control supplement ( $3.9 \mathrm{~g}$ high-oleic acid sunflower oil, HOSF), per day. The CLA capsule contained $65.9 \%$ CLA, of which the main constituents were $c 9 t 11$ isomer $(29.7 \%)$ and $c 10 t 12$ isomer $(30.9 \%)$, and also contained minimal amounts of other CLA isomers $(2.9 \%)$. In addition, the capsule contained oleic acid (18: $1 n-9,24.7 \%)$, and a small amount of palmitic acid (16: $0 ; 3.5 \%)$, stearic acid $(18: 0 ; 1.3 \%)$ and linoleic acid (18: $2 n ; 9 ; 12 ; 1.9 \%)$.

Experimental subjects and controls were tested prior to and at the end of the 12-week period of intervention. Every 2 weeks the subjects met with registered dietitians to report any adverse events (e.g. diarrhoea, bloating) or any changes in training, lifestyle or eating patterns, and to assess pill compliance. In addition, at each of these visits, subjects were asked to complete a visual analogue scale measuring hunger, fullness, satiety and prospective intake, prior to and for $3 \mathrm{~h}$ following the ingestion of a standardised breakfast snack.

Subjects underwent preliminary screening for cardio-respiratory fitness; body composition by skinfold measurements, dual-energy X-ray absorptiometry (DEXA) and computerised tomography (CT) scans at the level of L4/L5. Oral glucose tolerance tests (OGTT) were conducted and blood lipid profiles were measured. In addition, fasting RMR and RER, as well as RER during exercise at pre-set relative low- and high-intensity workloads $\left(25 \%\right.$ and $\left.65 \% \mathrm{~V}_{\mathrm{O} 2 \max }\right)$ were measured.

\section{Eating behaviour}

Prior to the intervention, the Three-Factor Eating questionnaire was administered to screen for individuals demonstrating restrained eating, or high levels of dietary disinhibition (Stunkard \& Messick, 1985).

\section{Dietary assessment}

Subjects completed three $4 \mathrm{~d}$ dietary records (three weekdays and one weekend day) during the trial, in weeks 1 (baseline), 6 and 12. These dietary records were coded by the same dietitian, and analysed with the Food Finder Program (Medtech, Tygerberg, South Africa). 


\section{Training}

Over the 12-week period, the subjects recorded their daily physical training which was then quantified according to metabolic equivalents (MET-h/week). In addition, physical activity was measured using a $7 \mathrm{~d}$ physical activity recall questionnaire prior to the start of the intervention, and at the end of the 12week period. Habitual activity was expressed as MET-h/wk (Blair et al. 1985). The subjects were instructed to keep their training and diet constant throughout the trial, and any changes were recorded.

\section{Body composition assessment}

Body composition assessments were undertaken immediately prior to and after 12 weeks of intervention. The anthropometric measurements, including the sum of seven skinfolds (biceps, triceps, subscapular, suprailiac, abdominal, thigh and calf), weight, height, and waist and hip circumferences were obtained. In addition, subjects underwent precise measurement of whole body, body composition using fan-beam DEXA.

CT was used to assess both visceral adipose tissue and subcutaneous adipose tissue area $\left(\mathrm{cm}^{2}\right)$; Yoshizumi et al. 1999), using a Toshiba X-press helical scanner (Japan). Subjects were scanned in the supine position with legs slightly flexed and arms raised above the head. Scans were done in arrested expiration at the L4/L5 level of the vertebra.

\section{Visual analogue scale measures of appetite}

Subjective motivation to eat (hunger, satiety, fullness and prospective consumption) was assessed by repeated administration of $100 \mathrm{~mm}$ visual analogue scales (VAS) (Flint et al. 2000) prior to a test breakfast in the fasted state (10-12 h) and then hourly for $3 \mathrm{~h}$ following the test meal. These VAS ratings were completed in the fasted state, every 2 weeks, through the 12-week intervention. The test breakfast comprised a $100 \mathrm{~g}$ muffin (Muffinmate CC, Cape Town, South Africa) and $200 \mathrm{ml}$ pure fruit juice (Parmalat, Stellenbosch, South Africa), which were individually packaged. The composition of the muffin per $100 \mathrm{~g}$ was $2749.4 \mathrm{~kJ}, 50.9 \mathrm{~g}$ protein, $31.6 \mathrm{~g}$ fat, $37.4 \mathrm{~g}$ carbohydrate, while the fruit juice contained $13.5 \mathrm{~g}$ carbohydrate $/ 100 \mathrm{ml}$.

\section{Oral glucose tolerance test and fasting blood lipid profiles}

Prior to starting the trial and after 12 weeks of supplementation the subjects underwent a standard OGTT after a 10-12 h overnight fast. A fasting blood sample $(20 \mathrm{ml})$ was drawn for the determination of plasma glucose and insulin concentrations, and serum triacylglycerol, total cholesterol, HDL-cholesterol, LDL-cholesterol and NEFA concentrations. The subjects then ingested $75 \mathrm{~g}$ glucose dissolved in $250 \mathrm{ml}$ water. Blood samples $(6 \mathrm{ml})$ were drawn at $30 \mathrm{~min}$ intervals for $2 \mathrm{~h}$ for the determination of plasma glucose and NEFA concentrations. Blood was drawn at 30 and 120 min post-glucose ingestion for determination of plasma insulin concentrations.

Plasma glucose concentrations were determined using the glucose oxidase method (Glucose Analyzer 2; Beckman Instruments, Fullerton, CA, USA) and plasma insulin concentrations were determined by non-specific insulin RIA
(Count-A-Coat Insulin; Diagnostic Products, Los Angeles, CA, USA) with intra-assay and inter-assay CV of $4.5 \%$ and $6.6 \%$, respectively. Serum NEFA concentrations were analysed with enzymatic spectrophotometric measurement using a commercial kit (NEFA Half-micro test; Roche, Mannheim, Germany). Blood lipids were analysed using the Roche Modular Auto Analyzer. Enzymatic colorimetric assays were used to analyse total cholesterol, triacylglycerol and HDL-cholesterol concentrations. The LDL-cholesterol concentrations were determined using the Friedewald Formula (Friedewald et al. 1972).

\section{Insulin sensitivity}

Insulin resistance and insulin sensitivity were estimated from fasting and glucose-stimulated blood glucose and insulin concentrations, based on the homeostasis (HOMA; Matthews et al. 1985) and the QUICKI (Perseghin et al. 2001) models.

The HOMA model is used as a proxy measure of insulin resistance and correlates well to insulin resistance measured using the euglycaemic-hyperinsulinaemic clamp (Matthews et al. 1985; Phillips et al. 1994). It is calculated using the following equation:

$$
\text { Resistance }=\text { insulin } /\left(22 \cdot 5 \mathrm{e}^{-\ln \text { glucose }}\right) .
$$

The QUICKI or Quantitative Insulin Sensitivity Check model has been shown to correlate well with insulin sensitivity measured using the euglycemic-hyperinsulinaemic clamp, however, a recent modification, incorporating fasting NEFA concentrations, further improves this association (Perseghin et al. 2001). The two equations used for this model are as follows:

$$
\begin{aligned}
\operatorname{QUICKI}\left(\mathrm{G}_{\mathrm{b}}, \mathrm{I}_{\mathrm{b}}\right)=1 /\left(\log \left(\mathrm{G}_{\mathrm{b}}\right)+\log \left(\mathrm{I}_{\mathrm{b}}\right)\right) \\
\begin{aligned}
\operatorname{QUICKI}\left(\mathrm{G}_{\mathrm{b}}, \mathrm{I}_{\mathrm{b}}, \operatorname{NEFA}_{\mathrm{b}}\right)= & 1 /\left(\log \left(\mathrm{G}_{\mathrm{b}}\right)+\log \left(\mathrm{I}_{\mathrm{b}}\right)\right. \\
& \left.+\log \left(\mathrm{NEFA}_{\mathrm{b}}\right)\right)
\end{aligned}
\end{aligned}
$$

where $\mathrm{G}_{\mathrm{b}}=$ fasting glucose concentration $(\mathrm{mg} / \mathrm{dl}) ; \mathrm{I}_{\mathrm{b}}=$ fasting insulin concentration $(\mu \mathrm{U} / \mathrm{ml}) ; \mathrm{NEFA}_{b}=$ fasting NEFA concentration $(\mathrm{mmol} / \mathrm{l})$.

Insulin secretion was also assessed using the $30 \mathrm{~min}$ insulin increment to the $30 \mathrm{~min}$ glucose increment. In addition, the attenuation of NEFA mobilisation during the OGTT was described.

Maximal oxygen uptake, energy expenditure and substrate utilisation at rest and in response to sub-maximal exercise

All subjects were tested for $\mathrm{V}_{\mathrm{O} 2 \max }$ and peak sustained power output on an electronically braked cycle ergometer (Lode, Groningen, The Netherlands) as described previously (Hawley \& Noakes, 1992). The results of the initial maximal test were used to determine the workload that corresponded to $25 \%$ and $65 \%$ of $\mathrm{V}_{\mathrm{O} 2 \max }$. The $\mathrm{CV}$ of measurement for the Oxycon Alpha was $1.4 \%$.

On another day, after a $10-12 \mathrm{~h}$ overnight fast, subjects arrived at the laboratory, and rested in the supine position for $30 \mathrm{~min}$ prior to the start of each test. Energy expenditure and substrate utilisation were assessed at rest, using the canopy or ventilated hood technique, by measuring $\mathrm{O}_{2}$ uptake and $\mathrm{CO}_{2}$ production at $60 \mathrm{~s}$ intervals for $20 \mathrm{~min}$ or until subjects reached steady state $(<5 \%$ change in RER) (VMax Metabolic Cart 
229; SensorMedics, Yorba Linda, CA, USA). From these measurements, the resting energy expenditure and RER were determined using the equations of Frayn (1983).

Following the resting measurements, sub-maximal exercise was performed by the subjects at two exercise intensities ( $25 \%$ and $65 \%$ of $\mathrm{V}_{\mathrm{O} 2 \mathrm{max}}$ ) for $15 \mathrm{~min}$ each on a cycle ergometer, with $15 \mathrm{~min}$ seated rest separating the two bouts. During the sub-maximal exercise session, substrate oxidation was calculated based on the gas exchange measured using a breath-by-breath OxyconSigma Analyser (Mijnhart, Bunnik, The Netherlands), as described previously.

\section{Statistical analysis}

Sample size was determined using GraphPad Instat ${ }^{\mathrm{TM}}$, version 2.05a (GraphPad, San Diego, CA, USA). In order to be able to detect differences in body fat mass $(\mathrm{kg})$ of $1.5 \mathrm{~kg}$ with a standard deviation of $1.75(\mathrm{~kg})$ and differences in body fat of $1.5 \%$ with a standard deviation of $2.0 \%$, at an alpha level of 0.05 , and with $80 \%$ power, we required a sample size of between fourteen and eighteen per group. This sample size takes into consideration the Bonferroni correction for multiple effects (gender and treatment). In addition, to detect differences in RMR of $0.6 \mathrm{MJ} / \mathrm{d}$ with a standard deviation of $0.7 \mathrm{MJ} / \mathrm{d}$, we required a sample size of fourteen per group.

Two-factor, repeated measures ANOVA was used to explore changes in body composition and metabolic parameters over time, between men and women, the CLA and control groups. Where there were significant effects attributed to gender differences, we subsequently adjusted for body composition. All results are presented as means and standard deviations, and $\alpha<0.05$ was considered to be statistically significant.

\section{Results}

\section{Subject characteristics}

Subjects were non-obese, regularly exercising men and women, with mean ages of 32 (SD 7) years. The mean BMI and $\mathrm{V}_{\mathrm{O} 2 \mathrm{max}}$ for men and women were $22.5(\mathrm{SD} 2 \cdot 5)$ and $24.2(\mathrm{SD} 2 \cdot 1) \mathrm{kg} / \mathrm{m}^{2}$, and 41.2 (SD 6.0) and 50.8 (SD 7.5) $\mathrm{ml} / \mathrm{kg}$ per min, respectively. Sub- ject characteristics are presented in Table 1. Groups were well matched for age, mass and anthropometrical characteristics. However, there was a significant difference in dietary restraint between the males in the control and CLA groups. When included as a covariate in the analysis, dietary constraint did not alter any of the subsequent relationships.

\section{Compliance and tolerance}

Sixty-two of the sixty-four subjects completed the trial. Two subjects withdrew from the trial, one due to personal reasons and the other due to medical reasons. The pill compliance was above $90 \%$ in both groups (93.9 (SD 6.5) v. 95.2 (SD 6.0) \%, for CLA and control groups, respectively). No subjects were excluded on the basis of non-compliance and co-varying for compliance in the statistical analysis did not alter any of the relationships.

The capsules were well-tolerated, with only a few subjects reporting sporadic adverse events. The adverse events reported in the CLA and control groups were headaches (6\% v. 16\%), bloating ( $29 \%$ v. $23 \%)$, diarrhoea $(48 \%$ v. $35 \%)$, flatulence $(16 \%$ v. $0 \%)$, skin irritation $(13 \% v .19 \%)$, and flu or cold ( $32 \%$ v. $42 \%)$, respectively. However, the occurrence of adverse events did not differ significantly between the groups.

\section{Body composition}

Body composition changes over the 12-week period are also presented in Table 1. CLA supplementation was not associated with any statistically significant changes in body mass or body composition in men or women. There were also no significant changes in regional body fat distribution in either group (Table 2), measured using either anthropometry (waist and hip circumferences) or CT.

\section{Glucose tolerance and insulin sensitivity}

The results of the OGTT are presented in Tables 3-5. Plasma glucose concentrations were not different in response to an oral glucose load in either of the groups and in men

Table 1. Body composition changes prior to (pre) and following (post) 12 weeks of conjugated linoleic acid (CLA) administration*

(Mean values and standard deviations)

\begin{tabular}{|c|c|c|c|c|c|c|c|c|}
\hline & \multicolumn{4}{|c|}{ CLA } & \multicolumn{4}{|c|}{ Control } \\
\hline & \multicolumn{2}{|c|}{ Pre } & \multicolumn{2}{|c|}{ Post } & \multicolumn{2}{|c|}{ Pre } & \multicolumn{2}{|c|}{ Post } \\
\hline & Mean & SD & Mean & SD & Mean & SD & Mean & SD \\
\hline \multicolumn{9}{|l|}{ Men } \\
\hline Mass $(\mathrm{kg})$ & $79 \cdot 6$ & $7 \cdot 8$ & $80 \cdot 2$ & $7 \cdot 8$ & 77.9 & $8 \cdot 2$ & $78 \cdot 0$ & 7.4 \\
\hline$\Sigma$ skinfolds $(\mathrm{mm})$ & $75 \cdot 2$ & $24 \cdot 3$ & 76.5 & $24 \cdot 8$ & 83.7 & $30 \cdot 8$ & 83.3 & 28.0 \\
\hline$\%$ Fat (DEXA) & $18 \cdot 2$ & 5.4 & $18 \cdot 6$ & $5 \cdot 7$ & $18 \cdot 3$ & 9.3 & $18 \cdot 8$ & $8 \cdot 2$ \\
\hline Fat-free (DEXA) (kg) & $62 \cdot 0$ & 5.5 & $62 \cdot 2$ & $5 \cdot 8$ & $60 \cdot 2$ & 4.7 & $60 \cdot 1$ & $4 \cdot 6$ \\
\hline \multicolumn{9}{|l|}{ Women } \\
\hline Mass $(\mathrm{kg})$ & $60 \cdot 0$ & 11.4 & 61.4 & 9.2 & $62 \cdot 4$ & $6 \cdot 3$ & $62 \cdot 3$ & $7 \cdot 1$ \\
\hline$\Sigma$ skinfolds $(\mathrm{mm})$ & $107 \cdot 0$ & 21.3 & $96 \cdot 9$ & $21 \cdot 2$ & 117.9 & $25 \cdot 0$ & $113 \cdot 8$ & $25 \cdot 7$ \\
\hline$\%$ Fat (DEXA) & $29 \cdot 2$ & 6.7 & $28 \cdot 2$ & $6 \cdot 4$ & 32.4 & $6 \cdot 1$ & 32.2 & $6 \cdot 1$ \\
\hline Fat-free (DEXA) (kg) & 41.9 & $4 \cdot 8$ & 41.7 & $5 \cdot 2$ & $40 \cdot 7$ & 3.5 & $40 \cdot 2$ & 3.7 \\
\hline
\end{tabular}

DEXA, dual-energy X-ray absorptiometry.

${ }^{*}$ For details of procedures, see Methods section. 
Table 2. Regional body composition prior to (pre) and following (post) 12 weeks of conjugated linoleic acid (CLA) administration* (Mean values and standard deviations)

\begin{tabular}{|c|c|c|c|c|c|c|c|c|}
\hline & \multicolumn{4}{|c|}{ CLA } & \multicolumn{4}{|c|}{ Control } \\
\hline & \multicolumn{2}{|c|}{ Pre } & \multicolumn{2}{|c|}{ Post } & \multicolumn{2}{|c|}{ Pre } & \multicolumn{2}{|c|}{ Post } \\
\hline & Mean & SD & Mean & SD & Mean & SD & Mean & SD \\
\hline \multicolumn{9}{|l|}{ Men } \\
\hline Waist (cm) & 87.9 & $8 \cdot 4$ & $88 \cdot 7$ & $6 \cdot 8$ & $89 \cdot 1$ & $5 \cdot 1$ & 88.9 & 4.9 \\
\hline Waist/hip ratio & 0.94 & 0.07 & 0.94 & 0.05 & 0.92 & 0.07 & 0.95 & 0.06 \\
\hline Visceral AT area $\left(\mathrm{cm}^{2}\right)$ & 6081 & 3242 & 6292 & 3029 & 5163 & 2584 & 5406 & 2517 \\
\hline Subcutaneous AT area $\left(\mathrm{cm}^{2}\right)$ & 12353 & 6459 & 12692 & 7201 & 13572 & 7515 & 14117 & 7393 \\
\hline \multicolumn{9}{|l|}{ Women } \\
\hline Waist (cm) & $75 \cdot 0$ & 4.9 & $73 \cdot 2$ & $6 \cdot 4$ & $77 \cdot 0$ & $6 \cdot 1$ & $76 \cdot 4$ & $5 \cdot 1$ \\
\hline Waist/hip ratio & 0.84 & 0.08 & 0.81 & 0.03 & 0.83 & 0.07 & 0.82 & 0.03 \\
\hline Visceral AT area $\left(\mathrm{cm}^{2}\right)$ & 3609 & 1530 & 3621 & 1534 & 4247 & 1754 & 4407 & 1900 \\
\hline Subcutaneous AT area $\left(\mathrm{cm}^{2}\right)$ & 15075 & 5127 & 14445 & 4866 & 20182 & 7341 & 20214 & 7681 \\
\hline
\end{tabular}

AT, adipose tissue.

* For details of procedures, see Methods section.

and women following the 12-week intervention period. Although plasma glucose concentrations were not different between groups, mean plasma insulin concentrations (at 0 , $30,120 \mathrm{~min}$ ) were statistically lower in women taking CLA following the 12-week intervention period, compared to the control group of women $(P=0.04$, gender $\times$ time $\times$ treatment interaction; mean values presented in Fig. 1). A significant association was found between the change in mean plasma insulin concentrations over the 12-week intervention, and the change in body fat $(r 0.36$, $P=0.032$ ). Similarly, mean serum NEFA concentrations were significantly attenuated in response to an oral glucose load after 12 weeks of supplementation in the CLA group compared to the control group $(P=0 \cdot 001$, time $\times$ treatment interaction).

Insulin sensitivity, as measured by the increment in glucose concentrations $(0-30 \mathrm{~min}) v$. the increment in insulin concentrations, and by the QUICKI model (Matsuda \&
DeFronzo, 1999; Perseghin et al. 2001), insulin resistance measured using the HOMA model (Matthews et al. 1985), and the fasting glucose/insulin ratio, were not significantly different between treatment or control groups, in men or women (Table 6).

\section{Blood lipid profiles}

Blood lipid profiles are presented in Table 7. Significant decreases were found in serum total cholesterol and LDL concentrations in both groups and decreases in HDL-cholesterol concentrations in women only, over the 12-week intervention ( $P=0.001, P=0.017$ and $P=0.02$, respectively). However, after covarying for body composition, these differences were no longer significant, nor were there significant changes in serum triacylglycerol concentrations in response to CLA supplementation.

Table 3. Changes in plasma glucose concentrations ( $\mathrm{mmol} / \mathrm{l})$ in response to an oral glucose load, prior to (Pre) and following (post) the 12-week conjugated linoleic acid (CLA) intervention period*

(Mean values and standard deviations)

\begin{tabular}{|c|c|c|c|c|c|c|c|c|c|c|}
\hline & \multicolumn{2}{|c|}{0} & \multicolumn{2}{|c|}{$30 \mathrm{~min}$} & \multicolumn{2}{|c|}{$60 \mathrm{~min}$} & \multicolumn{2}{|c|}{$90 \mathrm{~min}$} & \multicolumn{2}{|c|}{$120 \min$} \\
\hline & Mean & SD & Mean & SD & Mean & SD & Mean & SD & Mean & SD \\
\hline \multicolumn{11}{|l|}{ CLA } \\
\hline \multicolumn{11}{|l|}{ Men } \\
\hline Pre & 4.98 & 0.38 & 7.84 & 1.92 & $7 \cdot 12$ & 2.39 & 5.44 & $1 \cdot 31$ & 4.90 & 2.44 \\
\hline Post & 4.29 & 0.36 & 7.40 & $1 \cdot 10$ & $6 \cdot 23$ & 2.29 & $5 \cdot 30$ & 1.83 & 3.95 & $1 \cdot 13$ \\
\hline \multicolumn{11}{|l|}{ Women } \\
\hline Pre & 4.77 & 0.38 & $6 \cdot 72$ & 0.99 & 5.73 & 1.53 & $5 \cdot 22$ & $1 \cdot 21$ & 4.73 & 1.05 \\
\hline Post $†$ & 3.97 & 0.49 & $5 \cdot 38$ & 1.08 & 4.51 & 1.62 & 3.73 & 0.74 & 3.32 & 0.70 \\
\hline \multicolumn{11}{|l|}{ Control } \\
\hline \multicolumn{11}{|l|}{ Men } \\
\hline Pre & 4.96 & 0.34 & $7 \cdot 22$ & 1.13 & $6 \cdot 42$ & 1.65 & 4.99 & 1.21 & $4 \cdot 20$ & $1 \cdot 16$ \\
\hline Post† & 4.33 & 0.38 & $6 \cdot 57$ & 0.91 & 5.41 & 1.02 & 4.53 & 0.86 & $3 \cdot 61$ & 0.80 \\
\hline \multicolumn{11}{|l|}{ Women } \\
\hline Pre & 4.79 & 0.42 & 7.07 & 1.37 & $6 \cdot 48$ & $1 \cdot 84$ & $5 \cdot 80$ & 1.65 & 5.00 & 1.27 \\
\hline Post† & $4 \cdot 11$ & 0.28 & $6 \cdot 38$ & 1.22 & 5.45 & $1 \cdot 80$ & 4.59 & 1.25 & 3.98 & 1.28 \\
\hline
\end{tabular}

* For details of procedures, see Methods section.

$\dagger P<0.05$, plasma glucose concentrations were lower in both groups following the 12-week intervention. 
Table 4. Changes in plasma insulin concentration $(\mu \mathrm{U} / \mathrm{ml})$ in response to an oral glucose load, prior to (pre) and following (post) the 12-week conjugated linoleic acid (CLA) intervention period*

(Mean values and standard deviations)

\begin{tabular}{|c|c|c|c|c|c|c|c|c|c|c|c|c|}
\hline & \multicolumn{6}{|c|}{ CLA } & \multicolumn{6}{|c|}{ Control } \\
\hline & \multicolumn{2}{|c|}{0} & \multicolumn{2}{|c|}{$30 \mathrm{~min}$} & \multicolumn{2}{|c|}{$120 \min$} & \multicolumn{2}{|c|}{$0 \min$} & \multicolumn{2}{|c|}{$30 \mathrm{~min}$} & \multicolumn{2}{|c|}{$120 \mathrm{~min}$} \\
\hline & Mean & $\mathrm{SD}$ & Mean & SD & Mean & SD & Mean & $\mathrm{SD}$ & Mean & SD & Mean & SD \\
\hline \multicolumn{13}{|l|}{ Men } \\
\hline Pre & 5.5 & $2 \cdot 1$ & $45 \cdot 1$ & $19 \cdot 2$ & $18 \cdot 7$ & $16 \cdot 2$ & 4.9 & 3.1 & 37.6 & 24.3 & $21 \cdot 2$ & $20 \cdot 0$ \\
\hline $\begin{array}{c}\text { Post } \\
\text { Women }\end{array}$ & $6 \cdot 4$ & 3.4 & $53 \cdot 8$ & $25 \cdot 1$ & $22 \cdot 3$ & $20 \cdot 5$ & 5.9 & 3.4 & $49 \cdot 6$ & $23 \cdot 1$ & $19 \cdot 0$ & $18 \cdot 1$ \\
\hline Pre & 3.6 & 2.9 & $42 \cdot 4$ & 13.7 & $27 \cdot 0$ & $19 \cdot 1$ & 4.9 & $2 \cdot 7$ & 38.6 & $16 \cdot 5$ & $27 \cdot 7$ & $17 \cdot 2$ \\
\hline Post & $4 \cdot 1$ & 2.6 & 38.7 & 19.9 & 18.5 & $9 \cdot 1$ & $5 \cdot 8$ & $2 \cdot 3$ & 45.4 & $16 \cdot 3$ & $26 \cdot 7$ & $15 \cdot 1$ \\
\hline
\end{tabular}

* For details of procedures, see Methods section.

$\dagger P=0.05$, group $\times$ trial $\times$ time interaction.

\section{RMR, substrate utilisation at rest and during sub-maximal} exercise

Resting RER and RMR, expressed in absolute $(\mathrm{MJ} / \mathrm{d})$ or relative $(\mathrm{kJ} / \mathrm{kg}$ fat-free mass (FFM) per $\mathrm{d})$ terms, did not change in response to CLA treatment over 12 weeks, in either men or women. However, absolute RMR decreased with weight loss in both groups, and RER increased significantly from pre- to post-testing $(P<0 \cdot 001)$. There were also no significant differences in response to the CLA treatment over 12 weeks in substrate utilisation during sub-maximal exercise at $25 \%$ and $50 \%$ of $\mathrm{V}_{\mathrm{O} 2 \max }$ (Table 8).

\section{Ratings of hunger, fullness, prospective consumption and satisfaction}

CLA supplementation did not alter fasting measures of appetite at any stage during the trial in either men or women (data not shown). There were also no differences in perception of hunger, fullness, prospective consumption and satiety following the standardised breakfast. This was true, irrespective of whether the data were expressed as area under the curve, means or by comparing each timepoint. Mean values for satiety, in response to the standardised breakfast, over the 12-week intervention period are presented in Fig. 2.

\section{Dietary intake and training}

There were no systematic or statistically significant changes in nutrient or energy intake (data not shown), or in training frequency reported at the beginning, mid-way or at the end of the trial. In women, physical activity, measured as MET-h/week, was $13 \cdot 1(\mathrm{SD} 8 \cdot 3)$ and $11.2(\mathrm{SD} \mathrm{6.9)} \mathrm{h}$ at baseline and $13 \cdot 0$ (SD 8.3) and 9.4 (SD 7) h at 12 weeks in the CLA and control groups, respectively. In men, physical activity was 11.8 (SD 5.8) and 14.8 (SD 12.5) $\mathrm{h}$ at baseline and 14.7 (SD 5.9) and $10.8(\mathrm{SD} 5.9) \mathrm{h}$ at 12 weeks in the CLA and control groups, respectively.

\section{Discussion}

The main finding of the present study was that mixed isomer CLA administration ( $c 9 t 11$ isomer $(29.7 \%)$ and $c 10 t 12$ isomer $(30.9 \%), 3.9 \mathrm{~g} / \mathrm{d}$ for 12 weeks) significantly reduced plasma insulin concentrations in response to an oral glucose challenge, in non-obese regularly exercising women. Furthermore, NEFA concentrations were significantly attenuated in response to oral glucose, in both men and women in the CLA group. The changes in plasma insulin concentrations with CLA supplementation may be attributable, in part, to changes in body composition, as those individuals who lost the greatest amount of body fat also had an associated

Table 5. Changes in serum NEFA concentration ( $\mathrm{mmol} / \mathrm{l})$ in response to an oral glucose load, prior to (pre) and following (post) the 12-week conjugated linoleic acid (CLA) intervention period ${ }^{*}$

(Mean values and standard deviations)

\begin{tabular}{|c|c|c|c|c|c|c|c|c|c|c|c|c|}
\hline & \multicolumn{6}{|c|}{ CLA } & \multicolumn{6}{|c|}{ Control } \\
\hline & \multicolumn{2}{|c|}{0} & \multicolumn{2}{|c|}{$60 \mathrm{~min}$} & \multicolumn{2}{|c|}{$120 \mathrm{~min}$} & \multicolumn{2}{|c|}{$0 \mathrm{~min}$} & \multicolumn{2}{|c|}{$60 \mathrm{~min}$} & \multicolumn{2}{|c|}{$120 \mathrm{~min}$} \\
\hline & Mean & SD & Mean & SD & Mean & SD & Mean & SD & Mean & $S D$ & Mean & SD \\
\hline \multicolumn{13}{|l|}{ Men } \\
\hline Pre & 0.47 & 0.19 & 0.12 & 0.06 & 0.06 & 0.02 & 0.35 & 0.19 & 0.11 & 0.07 & 0.07 & 0.05 \\
\hline $\begin{array}{c}\text { Post } \\
\text { Women }\end{array}$ & 0.33 & 0.17 & 0.07 & 0.04 & 0.09 & 0.16 & 0.31 & 0.16 & 0.07 & 0.04 & 0.08 & 0.11 \\
\hline Pre & 0.49 & 0.35 & 0.07 & 0.06 & 0.04 & 0.03 & 0.43 & 0.23 & 0.08 & 0.07 & 0.05 & 0.03 \\
\hline Post & 0.32 & 0.20 & 0.04 & 0.03 & 0.05 & 0.06 & 0.45 & 0.23 & 0.07 & 0.04 & 0.03 & 0.05 \\
\hline
\end{tabular}

${ }^{*}$ For details of procedures, see Methods section.

$\dagger P<0.01$, group $\times$ trial $\times$ time interaction. 


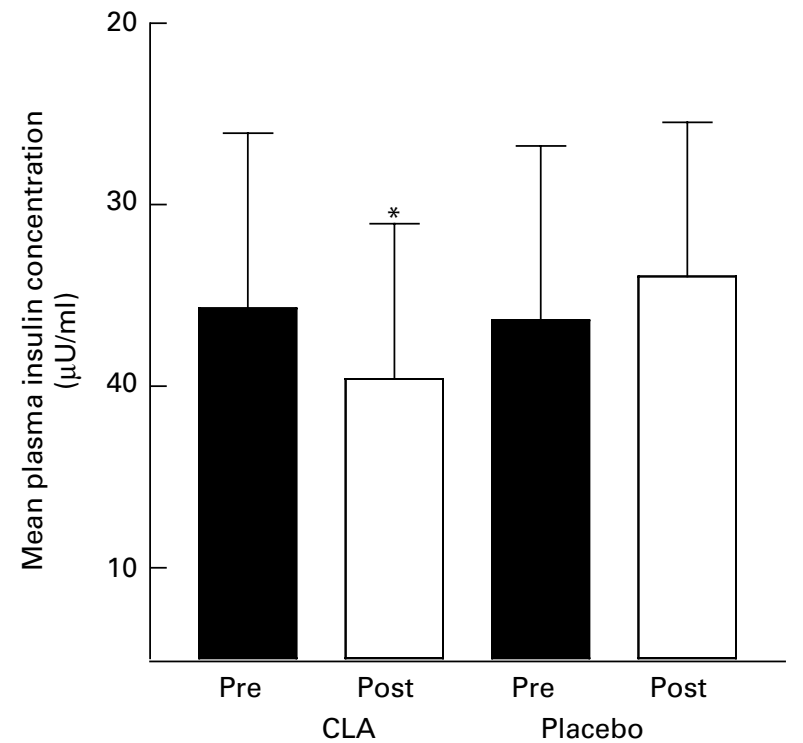

Fig. 1. Mean plasma insulin concentrations in women prior to (pre) and following (post) a 12-week intervention of conjugated linoleic acid (CLA). For details of procedures, see Methods section. Values are means with their standard deviations depicted by vertical bars. ${ }^{*} P=0.05$ for group $\times$ trial interaction.

decrease in mean plasma insulin concentrations ( $r$ 0.38, CLA group).

To our knowledge, this is the first controlled, clinical trial that has demonstrated this effect in normal-weight persons who are regularly exercising. Recently, a study undertaken in young, sedentary individuals found that 8 weeks of supplementation with a mixed isomer CLA, similar in content and dose to the present study, resulted in a significant decrease in mean fasting insulin concentrations, as well as an improved insulin sensitivity index in six of the ten subjects undergoing supplementation. This occurred despite no significant changes in body composition (Eyjolfson et al. 2004).
The results of Eyjolfson et al. (2004) are in contrast to previous studies in normoglycaemic individuals, in which CLA administration was associated with increased plasma insulin concentrations, suggesting decreased insulin sensitivity (Medina et al. 2000), and in Type 2 diabetics, in whom fasting glucose increased and insulin sensitivity decreased with CLA supplementation (Moloney et al. 2004). The apparent adverse effect of CLA supplementation on insulin resistance originally appeared to be isomerspecific. For example, in recent studies of abdominally obese men, treatment with dietary $t 10 c 12$ isomer-enriched CLA $(3.4 \mathrm{~g} / \mathrm{d}$ for 12 weeks) resulted in significantly increased insulin resistance and blood glucose levels, compared to the mixed isomer or placebo controls (Risérus et al. 2001). More recently, however, this same group of researchers studied twenty-five abdominally obese men, supplemented for 12 weeks with $c 9, t 11$-enriched CLA $(83 \%$; Risérus et al. 2004a). In their study, insulin sensitivity, as measured by the euglycaemic clamp technique, was reduced by $15 \%$ in the CLA group, compared to the control group. This is the first such study showing adverse effects of the $c 9 t 11$ isomer-enriched CLA on insulin sensitivity in man, and thus, the isomer-specific effects are not consistent.

The findings of reduced plasma insulin and serum NEFA concentrations in response to the same level of glycaemia in the present study may suggest improved insulin sensitivity with CLA supplementation in the already insulin-sensitive women. Differences between the work of Risérus et al. $(2001,2004 a, b)$ and the present study, as well as that of Eyolfson et al. (2004) may be due, in part, to the fact that subjects were young adults, and not overweight. Furthermore, in both of these studies, subjects were ingesting a similar amount of mixed-isomer CLA. However, further human studies are recommended, in order to determine the specific mechanisms underlying these effects, in particular, the isomer-specific nature of the adaptations, and any potential adverse effects and dose-response relationships in obese or insulin-resistant individuals.

Table 6. Measures of insulin sensitivity and insulin resistance prior to (pre) and following (post) the 12-week conjugated linoleic acid (CLA) intervention period*

(Mean values and standard deviations)

\begin{tabular}{|c|c|c|c|c|c|c|c|c|}
\hline \multirow[b]{3}{*}{ Measurest } & \multicolumn{4}{|c|}{ CLA } & \multicolumn{4}{|c|}{ Control } \\
\hline & \multicolumn{2}{|c|}{ Pre } & \multicolumn{2}{|c|}{ Post } & \multicolumn{2}{|c|}{ Pre } & \multicolumn{2}{|c|}{ Post } \\
\hline & Mean & SD & Mean & SD & Mean & SD & Mean & SD \\
\hline \multicolumn{9}{|l|}{ Men } \\
\hline $30 \mathrm{~min}$ insulin/glucose increment & $14 \cdot 2$ & $6 \cdot 9$ & $14 \cdot 7$ & $6 \cdot 2$ & $14 \cdot 4$ & $17 \cdot 5$ & $25 \cdot 2$ & $14 \cdot 8$ \\
\hline HOMA-R & $1 \cdot 21$ & 0.44 & $1 \cdot 22$ & 0.62 & 1.08 & 0.68 & $1 \cdot 15$ & 0.67 \\
\hline Fasting insulin/glucose & 1.07 & 0.51 & 0.96 & 0.75 & 1.43 & 1.07 & 1.79 & $3 \cdot 16$ \\
\hline QUICKI $\left(G_{b}, I_{b}\right)$ & 0.38 & 0.03 & 0.39 & 0.04 & 0.39 & 0.04 & 0.42 & $0 \cdot 12$ \\
\hline QUICKI $\left(G_{b}, I_{b}, N E F A_{b}\right)$ & 0.45 & 0.07 & 0.49 & 0.07 & 0.51 & 0.12 & 0.54 & $0 \cdot 18$ \\
\hline \multicolumn{9}{|l|}{ Women } \\
\hline $30 \mathrm{~min}$ insulin/glucose increment & $19 \cdot 1$ & $43 \cdot 8$ & $25 \cdot 1$ & $22 \cdot 1$ & $16 \cdot 5$ & $11 \cdot 3$ & $23 \cdot 1$ & $17 \cdot 1$ \\
\hline HOMA-R & 0.77 & 0.62 & 0.72 & 0.47 & 1.04 & 0.58 & 1.07 & 0.44 \\
\hline Fasting insulin/glucose & $3 \cdot 46$ & $5 \cdot 7$ & $2 \cdot 31$ & $3 \cdot 8$ & $1 \cdot 37$ & 0.94 & 0.96 & 0.80 \\
\hline QUICKI $\left(G_{b}, I_{b}\right)$ & 0.44 & 0.11 & 0.44 & 0.10 & 0.40 & 0.04 & 0.39 & 0.04 \\
\hline QUICKI $\left(G_{b}, I_{b}, N^{\prime} E F A_{b}\right)$ & 0.51 & $0 \cdot 11$ & 0.58 & $0 \cdot 18$ & 0.48 & 0.09 & 0.47 & 0.09 \\
\hline
\end{tabular}

* For details of procedures, see Methods section.

†For details of measures, see Methods section. 
Table 7. Serum lipid profiles prior to (pre) and following (post) the 12-week conjugated linoleic acid (CLA) intervention period*

(Mean values and standard deviations)

\begin{tabular}{|c|c|c|c|c|c|c|c|c|}
\hline & \multicolumn{4}{|c|}{ CLA } & \multicolumn{4}{|c|}{ Control } \\
\hline & \multicolumn{2}{|c|}{ Pre } & \multicolumn{2}{|c|}{ Post } & \multicolumn{2}{|c|}{ Pre } & \multicolumn{2}{|c|}{ Post } \\
\hline & Mean & SD & Mean & SD & Mean & SD & Mean & SD \\
\hline \multicolumn{9}{|l|}{ Men } \\
\hline $\mathrm{TC}(\mathrm{mmol} / \mathrm{l}) \dagger$ & 4.3 & 1.3 & $4 \cdot 1$ & 1.0 & 4.7 & 1.3 & 4.4 & 0.8 \\
\hline LDL-C (mmol/l) $\ddagger$ & $2 \cdot 2$ & 1.0 & $2 \cdot 0$ & 0.7 & $2 \cdot 7$ & $1 \cdot 2$ & $2 \cdot 4$ & 0.8 \\
\hline HDL-C (mmol/l/)§ & $1 \cdot 3$ & 0.5 & $1 \cdot 3$ & 0.4 & 1.3 & 0.3 & 1.4 & 0.3 \\
\hline $\mathrm{TG}(\mathrm{mmol} / \mathrm{l}) \|$ & 1.92 & 1.42 & 1.96 & 0.89 & 1.38 & 0.77 & $1 \cdot 28$ & 0.51 \\
\hline \multicolumn{9}{|l|}{ Women } \\
\hline $\mathrm{TC}(\mathrm{mmol} / \mathrm{l}) \dagger$ & 4.9 & $1 \cdot 2$ & 4.4 & 0.9 & 4.7 & $1 \cdot 1$ & $4 \cdot 1$ & 0.8 \\
\hline LDL-C (mmol/l) $\ddagger$ & 2.6 & $1 \cdot 1$ & $2 \cdot 4$ & 0.8 & 2.4 & 0.8 & $2 \cdot 2$ & 0.8 \\
\hline $\mathrm{HDL}-\mathrm{C}(\mathrm{mmol} / \mathrm{l}) \S$ & $1 \cdot 7$ & 0.4 & 1.5 & 0.4 & 1.6 & 0.3 & 1.4 & 0.3 \\
\hline $\mathrm{TG}(\mathrm{mmol} / \mathrm{l}) \|$ & $1 \cdot 16$ & 0.42 & $1 \cdot 14$ & 0.40 & 1.40 & 0.55 & $1 \cdot 14$ & 0.35 \\
\hline
\end{tabular}

HDL-C, HDL-cholesterol; LDL-C, LDL-cholesterol; TC, total cholesterol; TG, triacylglycerol.

${ }^{*}$ For details of procedures, see Methods section.

Changes pre-post in both groups: $\dagger P=0.001, \ddagger P=0.017 ; \S P=0.02$.

$\| P=0.03$, time $\times$ treatment interaction

In the present study, reduced plasma insulin concentrations at the same level of glycaemia in the CLA women were not reflected in the indexed measures of insulin resistance (HOMA) or insulin sensitivity (QUICKI), although there was a trend towards improved insulin sensitivity $(P<0.08)$. This is likely due to the fact that these indices have been developed, in part, to establish a more easily administered reference for insulin. In the current study sample, subjects were generally insulin-sensitive, and found to be at the higher range of values previously reported for non-diabetic, control populations for QUICKI, and at the very low range of values for HOMA-IR (Phillips et al. 1994; Perseghin et al. 2001). Therefore, these indices may not be as sensitive to change in the extreme ranges, and in non-diabetic, nonobese, fit individuals.

\section{Body composition}

In the present study we failed to find an association between CLA administration and changes in body composition. In human studies, the effects of CLA supplementation on body composition have been inconsistent. For example, in a small, placebo-controlled study of healthy, non-obese women, $3.9 \mathrm{~g} / \mathrm{d}$ mixed isomer CLA, containing smaller quantities of the $c 9 t 11$ and $t 10 c 12$ isomers, over $64 \mathrm{~d}$, had no effect on body fat content (Zambell et al. 2000). Conversely, in studies of overweight men and women (Blankson et al. 2000) and abdominally obese men (Risérus et al. 2001), CLA supplementation over several weeks (amounts ranged from 3.4 to $6.8 \mathrm{~g} / \mathrm{d}$ mixed isomer composition ( $>36 \% t 10 c 12$ and $c 9 t 11$ isomers) for 12 weeks, or $4.2 \mathrm{~g} /$ $\mathrm{d}$ for 4 weeks) resulted in significant body fat losses. In another recent study, as little as $1.8 \mathrm{~g} \mathrm{CLA} / \mathrm{d}$ resulted in a significant reduction in body fat percentage in healthy, non-overweight men and women, who exercised for $90 \mathrm{~min}$, three times weekly (Thom et al. 2001). Differences between studies may be linked, in part, to the composition of the placebo control capsules, or the isomeric mix of the CLA supplement.

As training and dietary intake did not change in the present study, it is unlikely that these factors played a confounding role for effects of CLA on body composition.

Table 8. RMR and RER at rest and during sub-maximal exercise at $25 \%$ and $50 \%$ of $\mathrm{V}_{\mathrm{O} \text { max }}$, prior to (pre) and following (post) the 12-week conjugated linoleic acid (CLA) intervention period*

(Mean values and standard deviations)

\begin{tabular}{|c|c|c|c|c|c|c|c|c|}
\hline & \multicolumn{4}{|c|}{ CLA } & \multicolumn{4}{|c|}{ Control } \\
\hline & \multicolumn{2}{|c|}{ Pre } & \multicolumn{2}{|c|}{ Post } & \multicolumn{2}{|c|}{ Pre } & \multicolumn{2}{|c|}{ Post } \\
\hline & Mean & SD & Mean & SD & Mean & SD & Mean & SD \\
\hline RMR $(M J / d) \dagger$ & $6 \cdot 5$ & $1 \cdot 0$ & $6 \cdot 3$ & $1 \cdot 1$ & $6 \cdot 8$ & $1 \cdot 1$ & $6 \cdot 4$ & $1 \cdot 1$ \\
\hline Resting RER $\left(\mathrm{V}_{\left.\mathrm{CO}_{2} / \mathrm{V}_{\mathrm{O}}\right) \dagger}\right)$ & 0.76 & 0.04 & 0.86 & 0.07 & 0.77 & 0.06 & 0.88 & 0.08 \\
\hline $\mathrm{RER}$ at $25 \% \mathrm{PPO}\left(\mathrm{V}_{\mathrm{CO}_{2}} / \mathrm{V}_{\mathrm{O}_{2}}\right)$ & 0.85 & 0.03 & 0.88 & 0.04 & 0.87 & 0.03 & 0.87 & 0.04 \\
\hline RER at $50 \%$ PPO $\left(\mathrm{V}_{\mathrm{CO}_{2}} / \mathrm{V}_{\mathrm{O} 2}\right)$ & 0.90 & 0.04 & 0.92 & 0.03 & 0.91 & 0.03 & 0.92 & 0.03 \\
\hline
\end{tabular}

PPO, peak sustained power output.

* For details of procedures, see Methods section.

†Changes pre-post in both groups, no group or interaction effects $(P<0.001)$. 

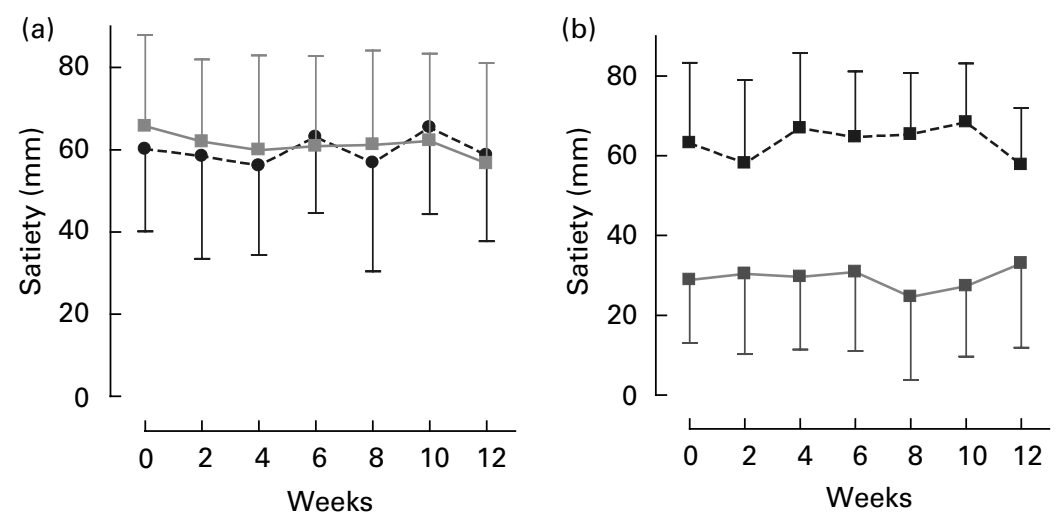

Fig. 2. Mean satiety scores for women (a) and men (b) for the conjugated linoleic acid (CLA, $\square$ ) and control groups ( $\bullet$, $\mathbf{\square}$ ). For details of procedures, see Methods section. Values are means with their standard deviations depicted by vertical bars. There were no effects of CLA on satiety, however, in the men, the control group had a higher overall satiety level (gender $\times$ group interaction, $P=0.02$ ).

\section{Regional adipose tissue distribution}

Unlike previous studies in abdominally obese individuals supplemented with CLA (Risérus et al. 2001), we were unable to detect differences in regional adipose tissue distribution, visceral or subcutaneous adipose tissue area, using anthropometrical measures and CT scans, which may not be sensitive enough to detect small changes in body fat distribution expected in non-obese, physically fit individuals.

\section{Plasma lipoprotein levels}

In the present study, we found a reduction in serum HDLcholesterol and total cholesterol concentrations, in both groups of women, however there was no treatment effect of CLA. This is in agreement with other human trials, in which CLA supplementation (at similar concentrations for reasonably similar time periods) did not significantly alter plasma lipoprotein or serum triacylglycerol concentrations in normal-weight and overweight individuals (Benito et al. 2000; Risérus et al. 2001). More recently, Noone et al. (2002) demonstrated that supplementation with a 50:50 blend of $c 9 t 11: t 10 c 12$ isomers of CLA for 8 weeks significantly reduced fasting triacylglycerol concentrations, whereas supplementation with an 80:20 blend of $c 9 t 11: t 10 c 12$ isomers of CLA reduced VLDL-cholesterol concentrations in fifty-one normolipidaemic subjects, without altering LDL-cholesterol or HDL-cholesterol concentrations.

The decrease in total cholesterol and HDL-cholesterol seen in both groups of women over the 12-week intervention period may be a consequence of increased awareness and self-monitoring of dietary intake, or the unlikely result of subtle changes in dietary fatty acid intake, and/or training. However, these changes are usually described in persons who have undergone weight loss (Sartorio et al. 2001).

The effects of dietary CLA supplementation (in the range of $0.1 \%$ of dietary energy) on lipoprotein metabolism are, thus far, inconsistent. The conflicting results regarding CLA supplementation and lipoprotein metabolism may be due to genetic susceptibility, differences in dose-response, isomer content and the levels of intake of dietary fat, and specific fatty acids. In addition, the placebo control used in trials varies greatly, including olive oil, linoleic acid, safflower oil, soya oil and sunflower oil. This may explain, in part, the lack of consistent results of CLA supplementation on plasma lipid profiles.

\section{Appetite and measures of satiety}

In the present study, CLA supplementation did not alter short-term appetite, measured using a VAS, nor hunger, satiety, fullness and desire to eat, preceding and for $3 \mathrm{~h}$ following a standardised breakfast. The present results are in agreement with a study by Medina et al. (2000), in a small sample of normal-weight women, in which appetite was measured over a 9-week period of CLA supplementation. Medina et al. (2000) postulated that this method may not be sufficiently sensitive to identify subtle changes in appetite.

In contrast, in a recent study by Kamphuis et al. (2003b), they observed increases in ratings of fullness and satiety and decreased ratings of hunger, in response to a standardised meal, in fifty-four overweight subjects over 13 weeks of supplementation at dosages of either 1.8 or $3.6 \mathrm{~g} \mathrm{CLA} / \mathrm{d}$. However, prior to CLA supplementation, subjects had followed a very low-energy diet $(2 \cdot 1 \mathrm{MJ} / \mathrm{d})$ for 3 weeks.

Differences between these studies may be a result of differences in energy or macronutrient composition of the standardised breakfast, or a consequence of protocol variations. For example, in the study by Kamphuis et al. (2003b), CLA supplementation was preceded by a short-term period of dieting, and consisted of a single pre-breakfast measure. In the present study, repeated VAS tests were conducted, before a standardised breakfast and in the $2 \mathrm{~h}$ period following the breakfast. It is also possible that hunger and satiety ratings should have been monitored for a longer period of time $(>4.5 \mathrm{~h})$, as the VAS technique is shown to be more valid and correlates best to subsequent energy intake if measured over $4 \mathrm{~h}$ following the standardised meal (Flint et al. 2000).

\section{Resting energy expenditure and substrate oxidation at rest and during exercise}

Finally, in the present study, we found no differences between treatment groups in changes in resting energy expenditure, or 
in substrate oxidation at rest associated with weight loss, nor during exercise. The present results are in agreement with the study by Zambell et al. (2000), in which no changes were found in resting energy expenditure, RER or fat oxidation at rest. In contrast, increased resting energy expenditure was demonstrated in overweight individuals who were supplemented with CLA after having lost weight, using very low-energy diets (Kamphuis et al. 2003a). In the present study, however, the increase in resting energy expenditure in the CLA group was not significant after adjusting for lean body mass.

\section{Conclusion}

The findings of the present study suggest that CLA $(3.9 \mathrm{~g} / \mathrm{d}$, 12 weeks) supplementation resulted in significant and favourable changes in plasma insulin and NEFA concentrations in response to an oral glucose load, suggesting improved insulin sensitivity. However, these changes were demonstrated in persons who were not overweight, and were found specifically in regularly exercising women. More studies are needed to further understand the mechanisms underlying these changes, and the possible modulating role of gender, fitness and body fat levels on the physiological response to CLA supplementation.

\section{Acknowledgements}

We thank the subjects who gave of their time without financial remuneration. Ryan Jankelowitz is thanked for his expert medical assistance. Jack Bergman and Debbie Steele of Symington and Partners and Tobie de Villiers are thanked for their extensive contribution to the research in terms of acquisition, analysis and interpretation of body composition data from the CT and DEXA scans, respectively. We are also grateful to Judy Belonje, for her expert technical assistance in performing the glucose and NEFA assays, and Jenny Ann Smuts, for her assistance in dietary analysis. This study was funded, in part, by Loders Croklaan, The Netherlands; RP Scherer, UK; Aspen Pharmacare, South Africa; and Technology and Human Resources for Industry Programme, South Africa. In addition, the UCT/MRC Research Unit for Exercise Science and Sports Medicine receives support from the Medical Research Council of South Africa, and the Nellie Atkinson and Harry Crossley Staff Research Funds of the University of Cape Town.

\section{References}

Benito P, Nelson GJ, Kelley DS, Bartolini G, Schmidt PC \& Simon V (2001) The effect of conjugated linoleic acid on plasma lipoproteins and tissue fatty acid composition in humans. Lipids 36, 229-236.

Blair SN, Haskell WL, Ho P, Paffenbarger RS Jr, Vranizan KM, Farquhar JW \& Wood PD (1985) Assessment of habitual physical activity by a seven-day recall in a community survey and controlled experiments. Am J Epidemiol 122, 794-804.

Blankson H, Stakkestad JA, Fargertun H, Thom E, Wadstein J \& Gudmundsen O (2000) Conjugated linoleic acid reduces body fat mass in overweight and obese humans. $J$ Nutr 130, $2943-2948$.
Eyjolfson V, Spriet LL \& Dyck DJ (2004) Conjugated linoleic acid improves insulin sensitivity in young, sedentary humans. Med Sci Sports Exerc 36, 814-820.

Flint A, Raben A, Blundell JE \& Astrup A (2000) Reproducibility, power and validity of visual analogue scales in assessment of appetite sensations in single test meal studies. Int J Obes Relat Metab Disord 24, 38-48.

Frayn KN (1983) Calculation of substrate oxidation rates in vivo from gaseous exchange. J Appl Physiol 55, 628-634.

Friedewald WT, Levy RI \& Fredrickson DS (1972) Estimation of the concentration of low-density lipoprotein cholesterol in plasma, without use of the preparative ultracentrifuge. Clin Chem 18, 499-502.

Hawley JA \& Noakes TD (1992) Peak sustained power output predicts $\mathrm{VO}_{2 \max }$ and performance time in trained cyclists. Eur $J$ Appl Physiol Occup Physiol 65, 79-83.

Houseknecht KL, Vanden Heuvel JP, Moya-Camarena SY, Portocarrero CP, Peck LW, Nickel KP \& Belury MA (1998) Dietary conjugated linoleic acid normalizes impaired glucose tolerance in the Zucker diabetic fatty fa/fa rat. Biochem Biophys Res Commun 244, 678-682.

Kamphuis MM, Lejeune MP, Saris WH \& Westerterp-Plantenga MS (2003a) The effect of conjugated linoleic acid supplementation after weight loss on body weight regain, body composition, and resting metabolic rate in overweight subjects. Int $J$ Obes Relat Metab Disord 27, 840-847.

Kamphius MMJW, Lejeune MPGM, Saris WHM \& Westerterp-Plantenga MS (2003b) The effect of conjugated linoleic acid supplementation after weight loss on appetite and food intake in overweight subjects. Eur J Clin Nutr 57, 1268-1274.

Matsuda M \& DeFronzo RA (1999) Insulin sensitivity indices obtained from oral glucose tolerance testing: comparison with the euglycaemic insulin clamp. Diab Care 22, 1462-1470.

Matthews DR, Hosker JP, Rudenski AS, Naylor BA, Treacher DF \& Turner RC (1985) Homeostasis model assessment: insulin resistance and beta-cell function from fasting plasma glucose and insulin concentrations in man. Diabetologia 28, $412-419$.

Medina EA, Horn WF, Keim NL, Havel PJ, Benito P, Kelley D, Nelson GJ \& Erickson KL (2000) Conjugated linoleic acid supplementation in humans: effects on circulating leptin concentrations and appetite. Lipids 35, 783-788.

Moloney F, Yeow T, Mullen A, Nolan JJ \& Roche HM (2004) Conjugated linoleic acid supplementation: insulin sensitivity, and lipoprotein metabolism in patients with type 2 diabetes mellitus. Am J Clin Nutr 80, 887-895.

Noone EJ, Roche HM, Nugent AP \& Gibney MJ (2002) The effect of dietary supplementation using isomeric blends of conjugated linoleic acid on lipid metabolism in healthy human subjects. Br J Nutr 88, 243-251.

Perseghin G, Caumo A, Caloni M, Testolin G \& Luzi L (2001) Incorporation of the fasting plasma FFA concentration into QUICKI improves its association with insulin sensitivity in non-obese individuals. J Clin Endocrinol Metab 86, 4776-4781.

Phillips DIW, Clark PM, Hales CN \& Osmond C (1994) Understanding oral glucose tolerance: comparison of glucose or insulin measurements during the oral glucose tolerance test with specific measurements of insulin resistance and insulin secretion. Diab Med 11, 286-292.

Rahman SM, Wang Y, Yotsumoto H, Cha J, Han S, Inoue S \& Yanagita T (2001) Effects of conjugated linoleic acid on serum leptin concentration, body-fat accumulation, and $\beta$-oxidation of fatty acid in OLEFT rats. Nutrition 17, 385-390.

Risérus U, Arner P, Brismar K \& Vessby B (2002) Treatment with dietary trans 10 cis 12 conjugated linoleic acid causes isomerspecific insulin resistance in obese men with the metabolic syndrome. Diabet Care 25, 1516-1521. 
Risérus U, Berglund L \& Vessby B (2001) Conjugated linoleic acid (CLA) reduced abdominal adipose tissue in obese middle-aged men with signs of the metabolic syndrome: a randomised controlled trial. Int $J$ Obes Relat Metab Disord 25, $1129-1135$.

Risérus U, Vessby B, Arnlov J \& Basu S (2004a) Effects of cis-9, trans11 conjugated linoleic acid supplementation on insulin sensitivity, lipid peroxidation, and proinflammatory markers in obese men. Am J Clin Nutr 80, 279-283.

Risérus U, Vessby B, Arner P \& Zethelius B (2004b) Supplementation with trans10cis12-conjugated linoleic acid induces hyperproinsulinaemia in obese men: close association with impaired insulin sensitivity. Diabetologia 47, 1016-1019.

Sartorio A, Lafortuna CL, Vangeli V, Tavani A, Bosetti C \& La Vecchia C (2001) Short-term changes of cardiovascular risk factors after a non-pharmacological body weight reduction program. Eur J Clin Nutr 55, 865-869.
Stunkard AJ \& Messick S (1985) The three-factor eating questionnaire to measure dietary restraint, disinhibition and hunger. $J$ Psychosom Res 29, 71-83.

Terpstra AH (2001) Differences between humans and mice in efficacy of the body fat lowering effect of conjugated linoleic acid: role of metabolic rate. $J$ Nutr 131, 2067-2068.

Thom E, Wadstein J \& Gudmundsen O (2001) Conjugated linoleic acid reduces body fat in healthy exercising humans. J Int Med Res $\mathbf{2 9}$, 392-396.

Yoshizumi T, Nakamura T, Yamane M, Islam AH, Menju M, Yamasaki K, Arai T, Kotani K, Funahashi T, Yamashita S \& Matsuzawa Y (1999) Abdominal fat: standardized technique for measurement at CT. Radiology 211, 283-286.

Zambell KL, Keim NL, Van Loan MD, Gale B, Benito P, Kelley DS \& Nelson GJ (2000) Conjugated linoleic acid supplementation in humans: effects on body composition and energy expenditure. Lipids 35, 777-782. 